\title{
A comparison of vestibular and auditory phenotypes in inbred mouse strains
}

\author{
Sherri M. Jones ${ }^{a},{ }^{*}$, Timothy A. Jones ${ }^{a}$, Kenneth R. Johnson ${ }^{b}$, Heping Yub, Lawrence C. \\ Erway ${ }^{\mathrm{C}}$, and Qing Y. Zheng ${ }^{\mathrm{A}}$ \\ aDepartment of Communication Sciences and Disorders, East Carolina University, Belk Annex, \\ Greenville and Charles Boulevards, Greenville, NC 27858, USA \\ bThe Jackson Laboratory, 600 Main Street, Bar Harbor, ME 04609, USA \\ cUniversity of Cincinnati, Cincinnati, OH 45221, USA
}

\begin{abstract}
The purposes of this research were to quantify gravity receptor function in inbred mouse strains and compare vestibular and auditory function for strain- and age-matched animals. Vestibular evoked potentials (VsEPs) were collected for 19 inbred strains at ages from 35 to 389 days old. On average, C57BL/6J (35 to 190 days), BALB/cByJ, C3H/HeSnJ, CBA/J, and young LP/J mice had VsEP thresholds comparable to normal. Elevated VsEP thresholds were found for elderly C57BL/ 6J, NOD.NONH2 ${ }^{\mathrm{kb}}$, BUB/BnJ, A/J, DBA/2J, NOD/LtJ, A/WySnJ, MRL/MpJ, A/HeJ, CAST/Ei, $\mathrm{SJL} / \mathrm{J}$, elderly $\mathrm{LP} / \mathrm{J}$, and $\mathrm{CE} / \mathrm{J}$. These results suggest that otolithic function varies among inbred strains and several strains displayed gravity receptor deficits by 90 days old. Auditory brainstem response (ABR) thresholds were compared to VsEP thresholds for 14 age-matched strains. C57BL/6J mice (up to 190 days) showed normal VsEPs with normal to mildly elevated ABR thresholds. Four strains (BUB/BnJ, NOD/LtJ, A/J, elderly LP/J) had significant hearing loss and elevated VsEP thresholds. Four strains (DBA/2J, A/WySnJ, NOD. NONH2 ${ }^{\mathrm{kb}}, \mathrm{A} / \mathrm{HeJ}$ ) had elevated VsEP thresholds (including absent VsEPs) with mild to moderate elevations in ABR thresholds. Three strains (MRL/MpJ, Ce/J, SJL/J) had significant vestibular loss with no concomitant hearing loss. These results suggest that functional change in one sensory system does not obligate change in the other. We hypothesize that genes responsible for early onset hearing loss may affect otolithic function, yet the time course of functional change may vary. In addition, some genetic mutations may produce primarily gravity receptor deficits. Potential genes responsible for selective gravity receptor impairment demonstrated herein remain to be identified.
\end{abstract}

\section{Keywords}

Vestibular; Auditory; Vestibular evoked potentials; Auditory brainstem response; Gravity receptor; Hearing

\section{Introduction}

The inner ear houses the sensory organs responsible for hearing and balance. The organ of Corti within the cochlea transduces sound, while the receptors within the two maculae and three ampullae transduce linear or angular motion of the head, respectively. Deficits in one

(C) 2006 Elsevier B.V. All rights reserved.

*Corresponding author. Fax: +1 252737 1111. jonessh@ecu.edu (S.M. Jones). 
or more of these organs or their neural innervation can lead to deafness, dizziness/ imbalance, or both. One per 1000 children are born with severe to profound hearing impairment, and many others develop significant hearing impairment before adulthood. The percentage of adults with hearing impairment increases with advanced age, and a significant portion of age-related hearing loss (as much as 30\%) is thought to be genetically based (see reviews by Nadol and Merchant, 2001; Petersen, 2002). Over 400 syndromes with associated hearing loss have been described (Gorlin et al., 1995). Nearly 100 loci have been identified for nonsyndromic hearing loss with genes identified for over 40 forms (Van Camp and Smith, Hereditary Hearing Loss Homepage: http://webhost.ua.ac.be/hhh/; also see reviews by Nadol and Merchant, 2001; Petit et al., 2001; Petersen, 2002; Bitner-Glindzicz, 2002).

Recent epidemiological studies from the National Institute on Deafness and Other Communication Disorders estimate that $3.4 \%$ of the US adult population or 6.2 million individuals experience chronic dizziness and/or imbalance. While the prevalence of these conditions is $9 \%$ among older adults, a significant number of young and middle aged adults also experience these problems (prevalence estimates of $1.7 \%$ and $3.7 \%$ for the $18-44$ and 45-64 age groups, respectively) (Hoffman and Sklare, 2003, D. Sklare and H. Hoffman, personal communication). Could there be a genetic basis for the dizziness in some of these individuals? Additionally, are there individuals wherein a vestibular impairment present at birth goes undetected because of compensation or adaptation? Vestibular dysfunction has been implicated as a potential cause of delayed motor development in children (e.g., Takiguchi et al., 1991; Tsuzuku and Kaga, 1992; Admiraal and Huygen, 1997; Kaga, 1999; Rine et al., 2000).

The mouse has a long history as a genetic model for hearing and balance dysfunction (e.g., Yerkes, 1907; Lord and Gates, 1929; Lyon, 1953; Deol, 1954; see also Ruben, 1991; Steel, 1995; Steel and Brown, 1994; Lyon et al., 1996; Petit et al., 2001; Ahituv and Avraham, 2002). Indeed, many mouse strains serve as animal models for human hereditary hearing impairment (e.g., Hereditary Hearing Impairment in Mice website at http://www.jax.org/research/hhim/, The Sanger Institute: Deaf Mouse Mutants website at http://www.sanger.ac.uk/PostGenomics/mousemutants/deaf/). Phenotyping auditory function has been instrumental in identifying strains with significant hearing impairment or with genetic susceptibility for age-related or noise-induced hearing loss. In addition, auditory functional testing facilitates our understanding of the functional consequences of genetic deficits and contributes to the continual discovery of genes responsible for hearing loss.

While much is being learned about the genetics of hearing impairment, relatively little is known about the role genes may play in vestibular dysfunction (i.e., vestibular impairment occurring in the absence of significant hearing impairment). Mice often show behaviors suggestive of balance problems (e.g., head bobbing, circling). Several mutant mouse strains with structural deficits of one or more of the semicircular canals were discovered by anatomical evaluation of the inner ears of circling mice (e.g., Kiernan et al., 2002; Hawker et al., 2005). Otoconia-deficient mouse strains were also discovered in mice with unusual head orientation or head motion (e.g., head tilt to one side, head bobbing, e.g., Sweet, 1980; Bergstrom et al., 1998; Ornitz et al., 1998). While behaviors can alert one to potential abnormalities and do provide important information about the output of the nervous system, they are indirect indices or correlates of inner ear function, can be due to abnormalities unrelated to the vestibular system, and can often be overtly normal due to compensation or adaptation. 
The purpose of the present study was two-fold. First, we surveyed inbred strains of mice for gravity receptor deficits. To do this, we evaluated gravity receptor function using linear vestibular evoked potentials (VsEPs). Linear VsEPs are compound action potentials from the vestibular portion of the eighth nerve and central relays in response to linear acceleration transients. (e.g., Jones, 1992; Jones and Jones, 1999; Jones et al., 1998a,b, 1999, 2002, 2004; Nazareth and Jones, 1998). They depend strictly upon the utricle and saccule (also known as the otolithic organs or gravity receptors) of the inner ear (Jones et al., 1999). Such recordings provide an objective test of the functional status of the peripheral and central gravity receptor sensory system.

Secondly, we identified inbred strains with potential selective vestibular impairment (i.e., significant gravity receptor impairment with no concomitant hearing impairment). To do this, we compared VsEP and ABR thresholds for age- and strain-matched mice. ABR thresholds for inbred strains were obtained from data published by Zheng et al. (1999), the Hereditary Hearing Impairment in Mice website (http://www.jax.org/hmr/screening.html) and the Mouse Phenome Database (http://aretha.jax.org/pub-cgi/phenome/mpdcgi?rtn=docs/home).

\section{Results}

VsEP response peaks increased in latency and decreased in amplitude as stimulus intensity was reduced until no response was visible at levels below threshold (Fig. 1). Normative screening ranges for comparison (i.e., \pm 2 standard deviations around the mean) were -5.5 to $-12.5 \mathrm{~dB}$ re: $1.0 \mathrm{~g} / \mathrm{ms}$ for VsEP thresholds. Normal VsEP response peak latencies (measured at a stimulus amplitude of $+6 \mathrm{~dB}$ re: $1.0 \mathrm{~g} / \mathrm{ms}$ ) ranged from 1188 to $1740 \mu \mathrm{s}$ for P1, 1996 to $2620 \mu$ s for P2, and 2888 to $3196 \mu$ s for P3. VsEP amplitudes (at $+6 \mathrm{~dB}$ re: 1.0 $\mathrm{g} / \mathrm{ms}$ ) ranged from 1.99 to $3.31 \mu \mathrm{V}$ for P1-N1 and 0.25 to $2.69 \mu \mathrm{V}$ for P2-N2 (Jones et al., 2005). These normative ranges were originally obtained from screening results on young C57BL/6J mice (35 days old), at an age where presumably there are not yet any structural deficits in the vestibular end organs (the C57BL/6J strain harbors a genetic mutation that leads to structural deficits with age; Johnson et al., 1997,2000). However, the normative range defined above is also consistent with VsEP results from two other inbred strains $(\mathrm{CBA} / \mathrm{CaJ}$ and $\mathrm{C} 3 \mathrm{HeB} / \mathrm{FeJ})$ that have no known structural deficits nor any known genetic mutations affecting the inner ear (Jones et al., 2005).

Gravity receptor function varied among inbred strains, most notably for VsEP thresholds (Fig. 2, Table 1). Amplitudes (not shown) were generally consistent with thresholds in that animals with elevated thresholds had smaller response peak amplitudes particularly for the peripheral response peak (i.e., P1-N1). Peak latencies were essentially within normal ranges for all strains tested (Fig. 3). On average, BALB/cByJ, C3H/HeSnJ, C57BL/6J (35, 92 and 190 days), and CBA/J, LP/J (45 days) had VsEP thresholds comparable to normal (as defined herein) at least at the ages tested here. Mean VsEP thresholds for SKH/2J-hr were borderline normal. Elevated VsEP thresholds were found for elderly C57BL/6J, A/HeJ, A/J, A/WySnJ, BUB/BnJ, CAST/Ei, CE/J, DBA/1LaJ, DBA/2J (both ages), JF1/MS, elderly LP/ J, MRL/ MpJ, NOD/LtJ (both ages), NOD.NONH2 ${ }^{\mathrm{kb}}$ (both ages), and SJL/J. In two strains (A/J and $\mathrm{CE} / \mathrm{J})$, all but one of the animals had no recordable responses at the maximum stimulus intensity.

Many, but not all, of the strains with elevated VsEP thresholds also demonstrated elevated ABR thresholds at a similar age (Fig. 4). C57BL/6J mice had relatively normal ABR and VsEP thresholds up to 190 days old. BUB/BnJ, NOD/LtJ, JF1/MS, and elderly LP/J had profound hearing loss and elevated VsEP thresholds. A/J, A/HeJ, A/WySnJ, young NOD. $\mathrm{NON}-\mathrm{H} 2^{\mathrm{kb}}$, and DBA/2J had elevated VsEP thresholds (including absent VsEPs) with mild 
to moderate elevations in ABR thresholds at the ages tested. Three strains (MRL/MpJ, CE/J, and SJL/J) had considerable elevations in VsEP thresholds by 90 days of age with no concomitant elevation in ABR thresholds.

\section{Discussion}

We have assessed gravity receptor function in a number of inbred mouse strains using linear VsEP screening strategies. These testing procedures show that gravity receptor function varies considerably among inbred mouse strains, most notably for VsEP thresholds. The results suggest that several inbred strains have reduced gravity receptor sensitivity by 2 to 3 months of age. Furthermore, none of these animals demonstrated imbalance behaviors, which suggests that the vestibular deficit would have been missed based on behavioral observation alone. Jones et al. (2005) studied mutant mouse strains and also showed that behavior (e.g., swimming and drop reflexes) was judged as normal in several strains where VsEPs were severely diminished. Normal behavior with reduced vestibular sensory input is not too surprising as vestibulomotor systems demonstrate remarkable plasticity and compensation (e.g., Curthoys and Halmagyi, 1995; Brandt et al., 1997).

Structurally, we know that the functional deficits identified here involve the peripheral apparatus but the deficits do not appear to be due to gross deficiencies in otoconia. Examination of cleared temporal bones (i.e., dissected bones dehydrated and cleared with methylsalicylate) at the light microscopic level evidenced normal appearing complements of otoconia over the utricle and saccule. Other structural elements (e.g., stereocilia, hair cells, primary afferents) must be evaluated to determine putative structural correlate(s) for the functional deficit. It is not possible to identify which gravity receptor organ (utricle or saccule) is affected from the present data alone. Linear VsEPs obtained with stimuli presented in the naso-occipital axis ( $\mathrm{Gx}$ axis) reflect activity of both the utricle and saccule (Jones et al., 1998a,b, 1999, 2004). Furthermore, the present study does not address the question of semicircular canal dysfunction since linear VsEPs measure the status of the gravity receptor organs selectively. This does not diminish the importance of the present results since the present study assays a portion of the vestibular labyrinth that is not well studied and provides our first insight regarding possible distinct sequelae for vestibular and auditory systems in the context of specific genetic mutations.

Although age was not a primary focus of the present study, the data do support the notion that peripheral gravity receptor function, like peripheral hearing, can decline with age. Several of the strains studied here carry genes that have been shown to contribute to or modify aging of hearing function including C57BL/6J, A/J, BALB/cByJ, BUB/BnJ, DBA/ 2J, NOD/LtJ, and SKH2/J (Johnson and Zheng, 2002; Johnson et al., 1997, 2000; NobenTrauth et al., 2003). We are currently evaluating similar questions for vestibular function and further are making a comparison between the two inner ear sensory systems in terms of functional senescence.

Comparing ABR and VsEP thresholds for age-matched animals suggests that functional change in one sensory system does not obligate change in the other. In addition, available $\mathrm{ABR}$ data show that $\mathrm{CE} / \mathrm{J}$ and $\mathrm{SJL} / \mathrm{J}$ strains retain good hearing (at least up to 400 days of age) or may develop a mild hearing loss at or beyond 1 year of age (Zheng et al., 1999). The early onset gravity receptor deficit in the absence of hearing loss (including significant agerelated hearing loss) suggests that selective vestibular dysfunction may occur. Hypothetically, these results suggest that the selective vestibular dysfunction has a genetic basis. Furthermore, we would hypothesize that the underlying genes causing a loss of vestibular function may be recessive because $\mathrm{F} 1$ hybrids between strains with normal VsEP thresholds (e.g., BALB/cByJ) and strains with elevated thresholds (e.g., A/J) exhibit normal 
VsEP thresholds (mean VsEP threshold for BALB $\times \mathrm{A} / \mathrm{J}$ F1 hybrids $(N=4)$ is $-7.5 \pm 0 \mathrm{~dB}$ re: $1.0 \mathrm{~g} / \mathrm{ms}$, unpublished observations).

In summary, linear VsEP and ABR testing procedures are direct measures of gravity receptor and cochlear function, respectively. Such measures are useful for quantifying the nature and severity of inner ear deficits, providing information regarding site of lesion (i.e., peripheral versus central) and evaluating the effects of age, genetics, gender, etc. on inner ear function. The present study used linear VsEPs to identify several inbred strains with early onset gravity receptor impairment, and a comparison of VsEP with ABR data revealed two strains with potential selective gravity receptor impairment.

\section{Experimental procedures}

Table 1 lists the strains, ages, and number of mice tested with VsEPs. VsEPs for three ages of C57BL/6J mice have been published recently (Jones et al., 2005) but are included in this dataset for comparison. Strains were selected based on three factors. First, the inbred strains tested are background strains for genetic mutants that we were studying. Secondly, a number of these strains were identified as strains of interest for the Mouse Phenome Database project (http://aretha.jax.org/pub-cgi/phenome/mpdcgi?rtn=docs/home). Thirdly, convenience and availability of animals played a role primarily in the number of animals that could be tested per strain.

Animals were weighed and anesthetized with EquiThesin $(4 \mu \mathrm{l} / \mathrm{g}$ body weight injected intraperitoneally; EquiThesin is a mixture of sodium-pentobarbital, chloral hydrate,magnesium sulfate, propylene glycol, ethanol, and water (see Jones et al., 1997 for complete recipe)). A head mount was placed on the cranium using methods published previously (Jones and Jones, 1999; Jones et al., 2002). The head mount was used to couple the cranium securely to a mechanical shaker for precise and controlled stimulation to the head. Stainless steel electrodes were placed epidurally at the midline just posterior to the lamdoidal suture (noninverting electrode), subcutaneously behind the left pinnae (inverting electrodes) and at the neck (ground). Mice were positioned supine on a heating pad with the nose positioned upward and the head mount was coupled securely to the shaker platform. Core body temperature was maintained at $37.0 \pm 0.2^{\circ} \mathrm{C}$. Data were collected at The Jackson Laboratory (Bar Harbor, ME), the University of Missouri (Columbia, MO), and East Carolina University (Greenville, NC). The use of animals reported herein was reviewed and approved by the Institutional Animal Care and Use Committee at each institution.

Vestibular stimuli and recording parameters have been detailed elsewhere (Jones and Jones, 1999; Jones et al., 2002). Briefly, stimuli were linear acceleration pulses, 2 ms duration, applied to the cranium in the naso-occipital $( \pm \mathrm{Gx})$ axis. Stimuli were presented at a rate of 16 pulses per second. Alternating stimulus polarity was used such that shaker motion "toggled" between upward and downward directions. Thus, head motion alternated in two directions along the naso-occipital axis. The output of a calibrated accelerometer, mounted on the shaker platform, was routed to an electronic differentiator to monitor the jerk component (i.e., the first derivative of acceleration) of the stimulus. Stimulus amplitude was quantified in decibels relative to $1.0 \mathrm{~g} / \mathrm{ms}\left(1.0 \mathrm{~g}=9.8 \mu \mathrm{m} / \mathrm{ms}^{2}\right)$. Maximum stimulus amplitude was $+6 \mathrm{~dB}$ re: $1.0 \mathrm{~g} / \mathrm{ms}$, which corresponds to a peak acceleration of $4 \mathrm{~g}$ and calculated peak platform displacement of $26 \mu \mathrm{m}$ (Jones et al., 2002).

VsEPs were recorded using traditional signal averaging. Electrophysiological activity was amplified (200,000x), filtered (300 to $3000 \mathrm{~Hz},-6 \mathrm{~dB}$ points), and digitized $(125,000 \mathrm{~Hz}$ ) beginning at stimulus onset. Two hundred fifty six responses were averaged to produce one response trace. Responses were replicated such that at least two waveforms were collected 
for each stimulus intensity. A threshold seeking protocol was used where stimulus intensity began at $+6 \mathrm{~dB}$ and waveforms were collected in quiet and in the presence of an intense forward masker ( 50 to $50,000 \mathrm{~Hz}, 116 \mathrm{~dB}$ SPL). The masker was used to verify the absence of auditory responses. Then, stimulus level was reduced in $6 \mathrm{~dB}$ steps until no response could be detected by visual inspection of the waveform. At that point, the stimulus intensity was reduced an additional $3 \mathrm{~dB}$ and waveforms were collected for intensity steps midway between those already used. In this manner, we were able to collect an intensity series in 3 $\mathrm{dB}$ steps encompassing stimulus levels above and below threshold.

The first three positive and negative response peaks were analyzed. Peak latencies were measured in microseconds from the onset of the stimulus to each positive response peak ( $\mathrm{P} 1$, $\mathrm{P} 2$, and P3). Peak to peak amplitudes were measured in microvolts from each positive response peak (P1 and $\mathrm{P} 2)$ to its respective negative response (N1 and N2) peak. Threshold measured in decibels re: $1.0 \mathrm{~g} / \mathrm{ms}$ was defined as the stimulus level midway between the jerk amplitude just producing a discernible response and that stimulus level which did not. Thresholds provide a measure of the general sensitivity of the gravity receptor system. Latencies provide a measure of the timing of neural transmission and conduction through the vestibular neural pathways. Amplitudes reflect the size and general synchrony of the population of neurons responding to the stimulus. Data for both genders were pooled since we did not have sufficient numbers to examine gender specifically. Unpublished data from our laboratory have not revealed any gender differences in VsEP response parameters.

ABR threshold data were obtained from the published sources noted previously. While mouse ABR data are available from a number of resources, recording methods often differ among laboratories, making it virtually impossible to group ABR data collected across laboratories. Therefore, the comparison ABR data used herein were collected by the same laboratory using the methods published by Zheng et al. (1999). From the individual mouse data, we calculated means and standard deviations for the $32 \mathrm{kHz}$ thresholds of age- and strain-matched mice. Age-matched data were not available for all strains. The $32 \mathrm{kHz}$ thresholds were chosen for comparison because significant hearing loss affecting all frequencies would likely be apparent for high frequency thresholds and age-related hearing loss (where the onset typically first appears in the higher frequencies) could be distinguished as well. Therefore, using the highest frequency data available would facilitate identification of any hearing loss regardless of the underlying etiology. The upper limit of "normal" for the $32 \mathrm{kHz}$ stimulus was defined by Zheng et al. (1999) as three standard deviations above the average $32 \mathrm{kHz}$ threshold obtained from CBA/CaJ mice (i.e., $54 \mathrm{~dB}$ peSPL). We used this defined limit for the comparison made in the present study.

\section{Acknowledgments}

This work was supported by NIH R01 DC04477. The authors thank M. Hartsock, W. Avniel, and K. Tregear for assistance with data analysis.

\section{REFERENCES}

Admiraal RJ, Huygen PL. Vestibular areflexia as a cause of delayed motor skill development in children with the CHARGE association. Int. J. Pediatr. Otorhinolaryngol 1997;39:205-222. [PubMed: 9152748]

Ahituv N, Avraham KB. Mouse models for human deafness: current tools for new fashions. Trends Mol. Med 2002;8:447-451. [PubMed: 12223317]

Bergstrom RA, You Y, Erway LC, Lyon MF, Schimenti JC. Deletion mapping of the head tilt (het) gene in mice: a vestibular mutation causing specific absence of otoliths. Genetics 1998;150:815822. [PubMed: 9755211] 
Bitner-Glindzicz M. Hereditary deafness and phenotyping in humans. Br. Med. Bull 2002;63:73-94. [PubMed: 12324385]

Brandt T, Strupp M, Arbusow V, Dieringer N. Plasticity of the vestibular system: central compensation and sensory substitution for vestibular deficits. Adv. Neurol 1997;73:297-309. [PubMed: 8959221]

Curthoys IS, Halmagyi GM. Vestibular compensation: a review of the oculomotor, neural, and clinical consequences of unilateral vestibular loss. J. Vestib. Res 1995;5(2):67-107. [PubMed: 7743004]

Deol MS. The anomalies of the labyrinth of the mutants varitint-waddler, shaker-2 and jerker in the mouse. J. Genet 1954;52:562-588.

Gorlin, RJ.; Roiello, HV.; Cohen, MM. Hereditary Hearing Loss and its Syndromes. Oxford: Oxford Univ. Press; 1995.

Hawker K, Fuchs H, Angelis MH, Steel KP. Two new mouse mutants with vestibular defects that map to the highly mutable locus on chromosome 4. Int. J. Audiol 2005;44(3):171-177. [PubMed: 15916118]

Hoffman HJ, Sklare DA. Vestibular system problems: righting the balance. Abstr.-Assoc. Res. Otolaryngol 2003;26:133.

Johnson KR, Zheng QY. Ahl2 a second locus affecting age-related hearing loss in mice. Genomics 2002;80:461-464. [PubMed: 12408962]

Johnson KR, Erway LC, Cook SA, Willott JF, Zheng QY. A major gene affecting age-related hearing loss in C57BL/6J mice. Hear. Res 1997;114:83-92. [PubMed: 9447922]

Johnson KR, Zheng QY, Erway LC. A major gene affecting age related hearing loss is common to at least ten inbred strains of mice. Nat. Genet 2000;27:191-194. [PubMed: 11175788]

Jones TA. Vestibular short latency responses to pulsed linear acceleration in unanesthetized animals. Electroencephalogr. Clin. Neurophysiol 1992;82:377-386. [PubMed: 1374706]

Jones TA, Jones SM. Short latency compound action potentials from mammalian gravity receptor organs. Hear. Res 1999;136:75-85. [PubMed: 10511626]

Jones SM, Jones TA, Shukla R. Short latency vestibular evoked potentials in the Japanese quail (Coturnix coturnix japonica). J. Comp. Physiol., A Sens. Neural Behav. Physiol 1997;180(6):631638.

Jones TA, Jones SM, Colbert S. The adequate stimulus for avian short latency vestibular responses to linear translation. J. Vestib. Res 1998a;8:253-272. [PubMed: 9626651]

Jones SM, Ryals BM, Colbert S. Vestibular function in Belgian Waterslager canaries. Hear. Res 1998b;121:161-169. [PubMed: 9682818]

Jones SM, Erway LC, Bergstrom RA, Schimenti JC, Jones TA. Vestibular responses to linear acceleration are absent in otoconia-deficient C57BL/6JEi-het mice. Hear. Res 1999;135:56-60. [PubMed: 10491954]

Jones SM, Subramanian G, Avniel W, Guo Y, Burkard RF, Jones TA. Stimulus and recording variables and their effects on mammalian vestibular evoked potentials. J. Neurosci. Methods 2002;118:23-31. [PubMed: 12191754]

Jones SM, Erway LC, Yu H, Johnson KR, Jones TA. Gravity receptor function in mice with graded otoconial deficiencies. Hear. Res 2004;191:34-40. [PubMed: 15109702]

Jones SM, Johnson KR, Yu H, Erway LC, Alagramam KN, Pollack N, Jones TA. A quantitative survey of gravity receptor function in mutant mouse strains. J. Assoc. Res. Otolaryngol 2005;6(4): 297-310. [PubMed: 16235133]

Kaga K. Vestibular compensation in infants and children with congenital and acquired vestibular loss in both ears. Int. J. Pediatr. Otorhinolaryngol 1999;49:215-224. [PubMed: 10519701]

Kiernan AE, Erven A, Voegeling S, Peters J, Nolan P, Hunter J, Bacon Y, Steel KP, Brown SD, Guenet JL. ENU mutagenesis reveals a highly mutable locus on mouse chromosome 4 that affects ear morphogenesis. Mamm. Genome 2002;13(3):142-148. [PubMed: 11919684]

Lord EM, Gates WH. Shaker, a new mutation in the house mouse (Mus musculus). Am. Nat. Hist 1929;68:435-442.

Lyon MF. Absence of otoliths in the mouse: an effect of the pallid mutant. J. Genet 1953;51:638-650. 
Lyon, MF.; Rastan, S.; Brown, SDM. Genetic Variants and Strains of the Laboratory Mouse. Vol. vols. 1 and 2. New York, NY: Oxford Univ. Press; 1996.

Nadol JB, Merchant SN. Histopathology and molecular genetics of hearing loss in the human. Int. J. Pediatr. Otorhinolaryngol 2001;61:1-15. [PubMed: 11576626]

Nazareth AM, Jones TA. Central and peripheral components of short latency vestibular responses in the chicken. J. Vestib. Res 1998;8:233-252. [PubMed: 9626650]

Noben-Trauth K, Zheng QY, Johnson KR. Association of cadherin 23 with polygenic inheritance and genetic modification of sensorineural hearing loss. Nat. Genet 2003;35:21-23. [PubMed: 12910270]

Ornitz DM, Bohne BA, Thalmann I, Harding GW, Thalmann R. Otoconial agenesis in tilted mutant mice. Hear. Res 1998;112:60-70. [PubMed: 9714575]

Petersen MB. Non-syndromic autosomal-dominant deafness. Clin. Genet 2002;62:1-13. [PubMed: 12123480]

Petit C, Levilliers J, Hardelin JP. Molecular genetics of hearing loss. Annu. Rev. Genet 2001;35:589646. [PubMed: 11700295]

Rine RM, Cornwall G, Gan K, LoCascio C, O'Hare T, Robinson E, Rice M. Evidence of progressive delay of motor development in children with sensorineural hearing loss and concurrent vestibular dysfunction. Percept. Mot. Skills 2000;90:1101-1112. [PubMed: 10939054]

Ruben RJ. The history of the genetics of hearing impairment. Ann. N. Y. Acad. Sci 1991;630:6-15. [PubMed: 1952624]

Steel KP. Inherited hearing defects in mice. Annu. Rev. Genet 1995;29:675-701. [PubMed: 8825490]

Steel KP, Brown SD. Genes and deafness. Trends Genet 1994;10:428-435. [PubMed: 7871592]

Sweet HO. Head tilt (het). Mouse News Lett 1980;63:19.

Takiguchi T, Honda M, Kaga K, Myokai K, Ogawa T, Goto S. Results of damped-rotation tests in brain damaged infants and children. Acta Oto-Laryngol 1991;481:536-542.

Tsuzuku T, Kaga K. Delayed motor function and results of vestibular function tests in children with inner ear anomalies. Int. J. Pediatr. Otorhinolaryngol 1992;23:261-268. [PubMed: 1375590]

Yerkes, RM. The Dancing Mouse: A Study in Animal Behavior. The Animals Behavior Series 1. New York, NY: Macmillan Co.; 1907.

Zheng QY, Johnson KR, Erway LC. Assessment of hearing in 80 inbred strains ofmice by ABR threshold analyses. Hear. Res 1999;130:94-107. [PubMed: 10320101] 


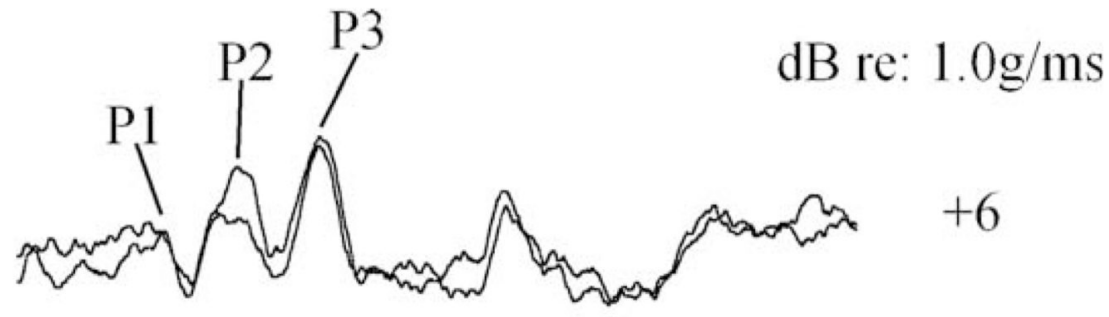

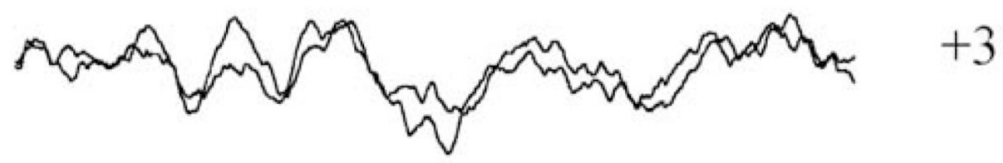

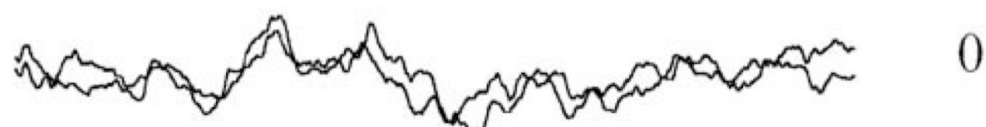

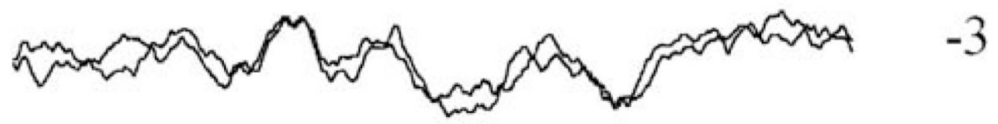

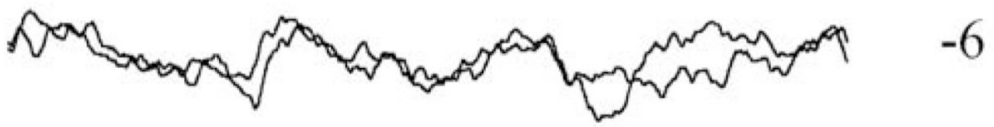

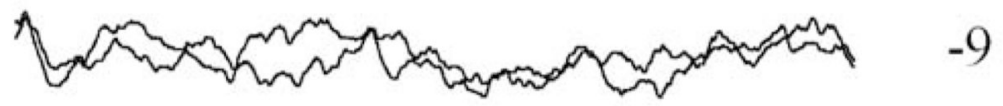

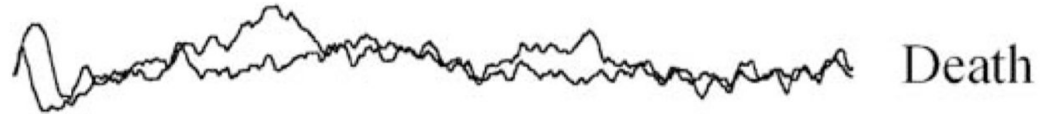

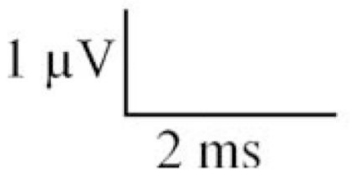

Fig. 1.

Representative VsEP intensity series for one mouse. This series of VsEPs was collected for one BALB/cByJ mouse. Intensities in decibels re: $1.0 \mathrm{~g} / \mathrm{ms}$ appear to the right of each pair of waveforms. Two waveforms at each stimulus level demonstrate that responses replicate. Positive response peaks are labeled. Threshold for this animal was scored at $-7.5 \mathrm{~dB}$ re: 1.0 $\mathrm{g} / \mathrm{ms}$. Total time represented for each waveform is $8 \mathrm{~ms}$. 


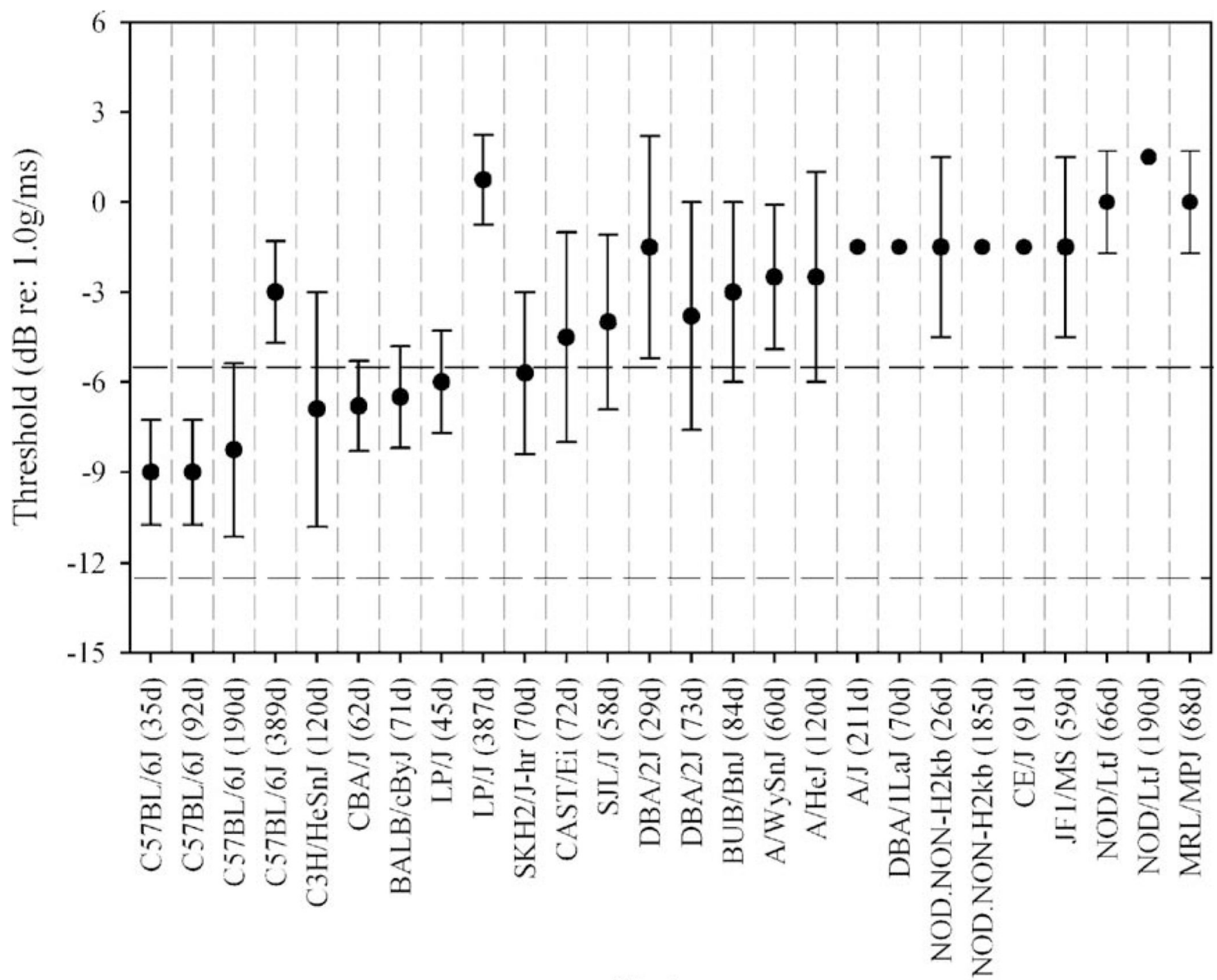

\section{Strain}

Fig. 2.

Mean VsEP thresholds for 19 inbred strains. Some strains were measured at two ormore ages. Age at testing is shown in parentheses. Normative ranges for young C57 mice $( \pm 2$ standard deviations) are shown by horizontal dashed lines. Elevated thresholds for elderly C57BL/6J and LP/J mice suggest age-related functional changes. Several inbred strains have elevated VsEP thresholds. Many, but not all of these strains, also have hearing loss. Error bars reflect standard deviation. 


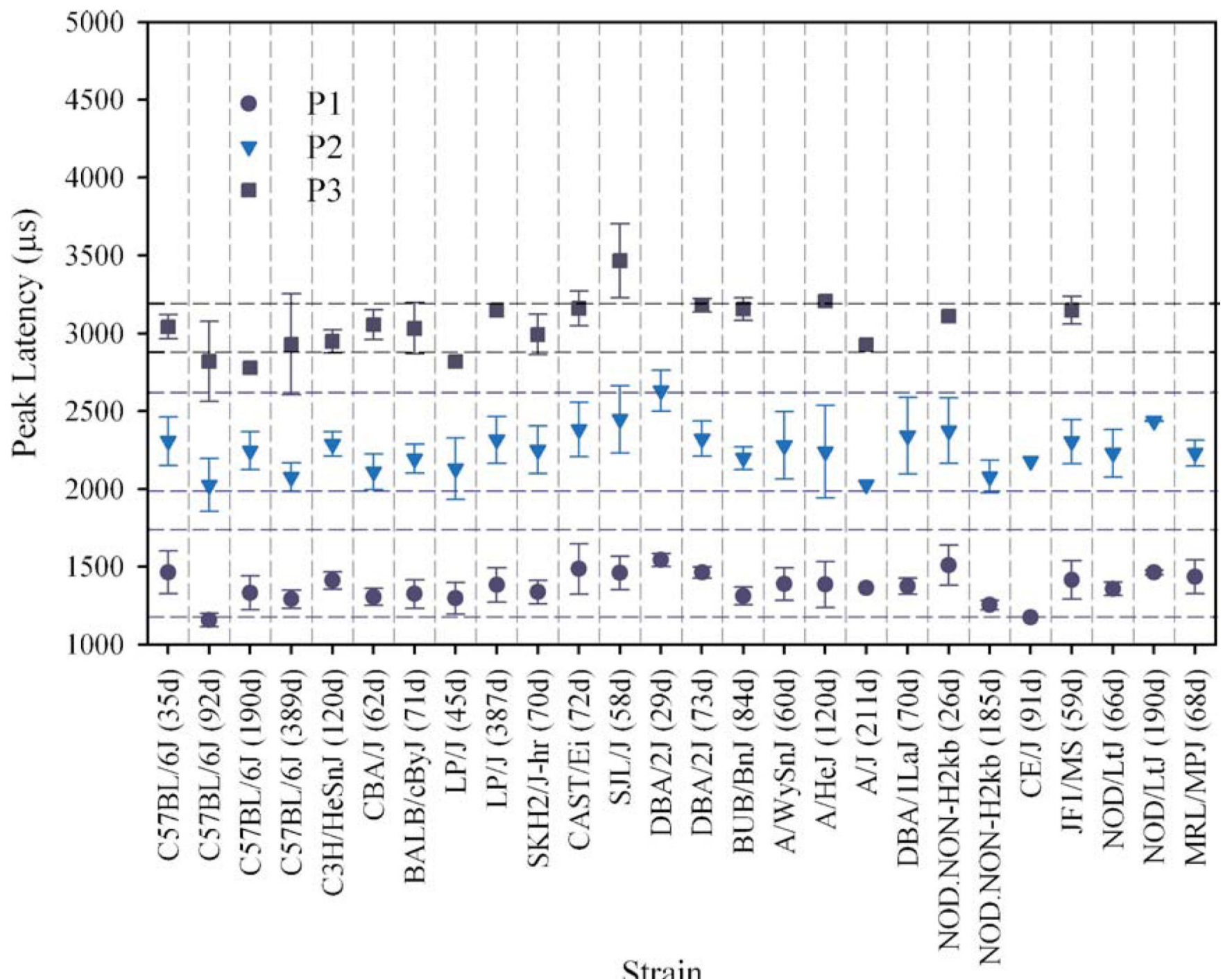

Fig. 3.

Mean VsEP latencies for 19 inbred strains. Some strains were measured at two or more ages.

Response peaks P1 (generated by the peripheral portion of the vestibular nerve), P2, and P3

(generated by central relay circuits) are shown. Horizontal dashed lines demonstrate

normative ranges for each response peak ( \pm 2 standard deviations). Despite significant variability in VsEP thresholds among these inbred strains, VsEP response peak latencies were essentially within normal limits. Error bars reflect standard deviation. 


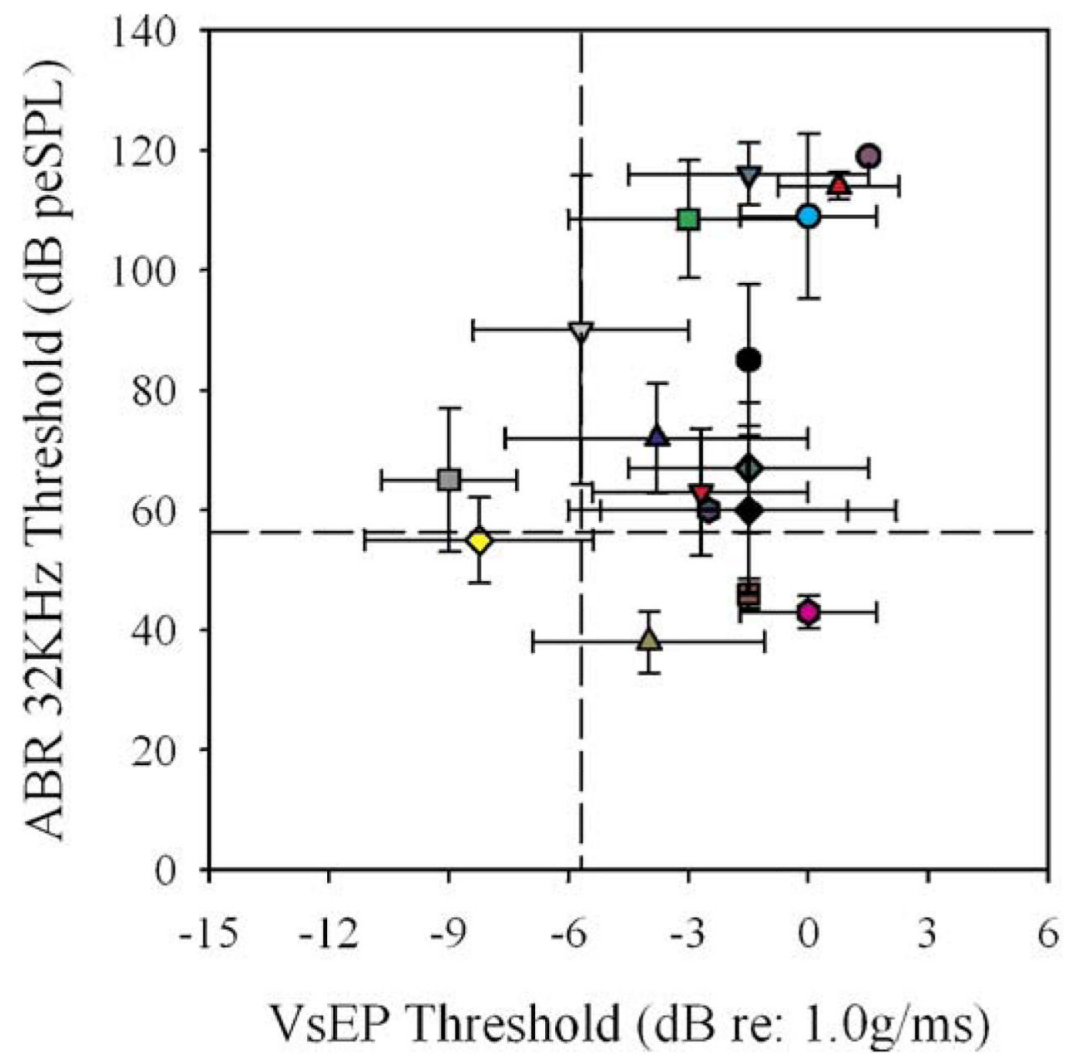

\begin{tabular}{|c|c|}
\hline$\square$ & C57/BL6J (92d) \\
\hline$\diamond$ & C57/BL6J (190d) \\
\hline$\nabla$ & $\mathrm{SKH} 2 / \mathrm{J}$ (70d) \\
\hline$\square$ & $\mathrm{BUB} / \mathrm{BnJ}(84 \mathrm{~d})$ \\
\hline$\nabla$ & JF1/MS (59d) \\
\hline$\Delta$ & $\mathrm{LP} / \mathrm{J}(387 \mathrm{~d})$ \\
\hline 0 & $\mathrm{NOD} / \mathrm{LtJ}(66 \mathrm{~d})$ \\
\hline ० & NOD/LtJ (190d) \\
\hline$\bullet$ & $\mathrm{DBA} / 2 \mathrm{~J}(29 \mathrm{~d})$ \\
\hline$\Delta$ & $\mathrm{DBA} / 2 \mathrm{~J}(73 \mathrm{~d})$ \\
\hline - & $\mathrm{A} / \mathrm{J}(211 \mathrm{~d})$ \\
\hline$\nabla$ & $\mathrm{A} / \mathrm{WySnJ}(60 \mathrm{~d})$ \\
\hline 0 & $\mathrm{~A} / \mathrm{HeJ}(120 \mathrm{~d})$ \\
\hline$\diamond$ & NOD NON-H $2^{k b}(26 d)$ \\
\hline$\Delta$ & $\mathrm{SJL} / \mathrm{J}(58 \mathrm{~d})$ \\
\hline ם & CE/J (90d) \\
\hline o & MRL/MpJ (68d) \\
\hline
\end{tabular}

Fig. 4.

Mean ABR and VsEP thresholds for 14 inbred strains. ABR thresholds for $32 \mathrm{kHz}$ tone bursts compared to VsEP thresholds for age-matched animals. Strains are listed in the right panel (age in days in parentheses). Similar results were found for comparisons with other stimuli used to elicit ABRs (clicks, $8 \mathrm{kHz}$ and $16 \mathrm{kHz}$ tone bursts). Some strains show elevated ABR and VsEP thresholds. Three strains (SJL/J, CE/J, and MRL/MpJ) show elevated VsEP thresholds but no concomitant hearing loss. The dashed lines depict the upper limits of normative ranges for VsEPs (vertical line) and ABRs (horizontal line from Zheng et al., 1999). The lower left quadrant reflects normal VsEP and ABR thresholds, the lower right quadrant reflects abnormal VsEP with normal ABR thresholds, the upper right reflects abnormal VsEP and ABR thresholds, and the upper left reflects normal VsEP and abnormal ABR. Error bars reflect standard deviation. 


\section{Table 1}

Strains tested, gender (number of animals), age at time of testing, number with no response, and mean VsEP threshold ( \pm standard deviation) in decibels re: $1.0 \mathrm{~g} / \mathrm{ms}$

\begin{tabular}{|c|c|c|c|c|}
\hline Strain & Gender $(N)$ & Age \pm SD (days) & NR & Threshold \\
\hline $\mathrm{A} / \mathrm{J}$ & $\mathrm{M}(4)$ & $211 \pm 0$ & 3 & -1.5 \\
\hline $\mathrm{A} / \mathrm{HeJ}$ & M (3) & $120 \pm 0$ & & $-2.5 \pm 3.5$ \\
\hline A/WySnJ & $\mathrm{F}(8), \mathrm{M}(2)$ & $60 \pm 4$ & 4 & $-2.5 \pm 2.4$ \\
\hline BALB/cByJ & $\mathrm{F}(1), \mathrm{M}(3)$ & $71 \pm 0$ & & $-6.5 \pm 1.7$ \\
\hline $\mathrm{BUB} / \mathrm{BnJ}$ & F (4) & $84 \pm 0$ & & $-3.0 \pm 3.0$ \\
\hline $\mathrm{C} 3 \mathrm{H} / \mathrm{HeSnJ}$ & $\mathrm{F}(3), \mathrm{M}(2)$ & $120 \pm 55$ & & $-6.9 \pm 3.9$ \\
\hline C57BL/6J & M (4) & $35 \pm 2$ & & $-9.0 \pm 1.7$ \\
\hline C57BL/6J & M (4) & $92 \pm 3$ & & $-9.0 \pm 1.7$ \\
\hline C57BL/6J & $\mathrm{F}(4)$ & $190 \pm 0$ & & $-8.3 \pm 2.3$ \\
\hline C57BL/6J & $\mathrm{F}(4)$ & $389 \pm 0$ & & $-3.0 \pm 1.7$ \\
\hline Cast/Ei & $\mathrm{F}(4)$ & $72 \pm 1$ & & $-4.5 \pm 3.5$ \\
\hline $\mathrm{CBA} / \mathrm{J}$ & $\mathrm{F}(2), \mathrm{M}(2)$ & $62 \pm 0$ & & $-6.8 \pm 1.5$ \\
\hline $\mathrm{CE} / \mathrm{J}$ & $\mathrm{M}(5)$ & $91 \pm 0$ & 4 & -1.5 \\
\hline DBA/1LaJ & $\mathrm{F}(2), \mathrm{M}(2)$ & $70 \pm 8$ & & $-1.5 \pm 0.0$ \\
\hline $\mathrm{DBA} / 2 \mathrm{~J}$ & $\mathrm{~F}(3), \mathrm{M}(2)$ & $29 \pm 0$ & & $-1.5 \pm 3.7$ \\
\hline $\mathrm{DBA} / 2 \mathrm{~J}$ & M (5) & $73 \pm 0$ & 1 & $-3.8 \pm 3.8$ \\
\hline $\mathrm{JF} 1 / \mathrm{MS}$ & $\mathrm{F}(5), \mathrm{M}(1)$ & $59 \pm 0$ & 3 & $-1.5 \pm 3.0$ \\
\hline $\mathrm{LP} / \mathrm{J}$ & $\mathrm{M}(4)$ & $45 \pm 0$ & & $-6.0 \pm 1.7$ \\
\hline $\mathrm{LP} / \mathrm{J}$ & F (4) & $387 \pm 0$ & & $0.8 \pm 1.5$ \\
\hline MRL/MpJ & M (4) & $68 \pm 0$ & & $0.0 \pm 1.7$ \\
\hline $\begin{array}{l}\text { NOD.NON- } \\
\mathrm{H} 2^{\mathrm{kb}}\end{array}$ & $\mathrm{F}(3)$ & $26 \pm 0$ & & $-1.5 \pm 3.0$ \\
\hline $\begin{array}{l}\text { NOD.NON } \\
\mathrm{H} 2^{\mathrm{kb}}\end{array}$ & $\mathrm{F}(2), \mathrm{M}(2)$ & $185 \pm 0$ & & $-1.5 \pm 0.0$ \\
\hline $\mathrm{NOD} / \mathrm{LtJ}$ & $\mathrm{F}(2), \mathrm{M}(2)$ & $66 \pm 0$ & & $0.0 \pm 1.7$ \\
\hline $\mathrm{NOD} / \mathrm{LtJ}$ & $\mathrm{M}(2)$ & $190 \pm 0$ & & $1.5 \pm 0.0$ \\
\hline $\mathrm{SKH} 2 / \mathrm{J}-\mathrm{hr}$ & $\mathrm{F}(2), \mathrm{M}(3)$ & $70 \pm 0$ & & $-5.7 \pm 2.7$ \\
\hline $\mathrm{SJL} / \mathrm{J}$ & $M(6)$ & $58 \pm 9$ & & $-4.0 \pm 2.9$ \\
\hline
\end{tabular}

$\mathrm{F}=$ female, $\mathrm{M}=$ male,$N=$ number tested, $\mathrm{NR}=$ no response. 